\title{
A clinical study on ultrasonographic measurement of cervical length at 18-24 weeks of gestation and pregnancy outcome
}

\author{
Jayati Nath $^{1}$, Bhattacharjee A. K. ${ }^{2}$, Talukdar R. K. ${ }^{2}$ \\ ${ }^{1}$ Department of Obstetrics \& Gynaecology, MMIMSR, Ambala, Haryana, India \\ ${ }^{2}$ Department of Obstetrics \& Gynaecology, GMCH, Guwahati, Assam, India
}

Received: 27 January 2016

Accepted: 01 March 2016

*Correspondence:

Dr. Jayati Nath,

E-mail: jayati.nath@yahoo.com

Copyright: $\odot$ the author(s), publisher and licensee Medip Academy. This is an open-access article distributed under the terms of the Creative Commons Attribution Non-Commercial License, which permits unrestricted non-commercial use, distribution, and reproduction in any medium, provided the original work is properly cited.

\begin{abstract}
Background: Preterm labour and preterm birth is the leading cause of perinatal mortality, whose incidence is approximately $10 \%$ of all live births worldwide. This study was undertaken to evaluate the cervical length ultrasonographically at 18 to 24 weeks of gestation in asymptomatic women and study the pregnancy outcomes and predicting risk of preterm labour and delivery.

Methods: This hospital based prospective study was conducted by enrolling 1500 antenatal patients with gestations between 18 and 24 weeks, after fulfilling the inclusion and exclusion criteria. Their cervical lengths were measured by USG and they followed through their pregnancy, labour and delivery \& all the relevant data were recorded, studied \& statistically analysed.

Results: Out of 1500 patients enrolled, 90 were lost to follow up. Therefore, all the result analyses were done for 1410 patients. Majority of the patients belonged to age group $21-30$ years $(830=58.86 \%)$, primigravida $(47.87 \%)$, from urban background (67.17\%), belonged to lower socio-economic status (61.70\%), at 21 weeks of gestation (28.15\%). 960 patients had labour at term (68.08\%), 360 (25.54\%) had preterm and 90 (6.38\%) had postterm labour. With cervical length $<1.5 \mathrm{~cm}$, all 15 patients went into preterm labour (100\%), cervical length $1.5-2.0 \mathrm{~cm}, 75$ patients (92.59\%) went into preterm labour, $2.1-2.5 \mathrm{~cm}$ cervical length 151 patients $(66.81 \%)$ went into preterm labour, 2.6$3.0 \mathrm{~cm} 48$ patients $(13.79 \%$ )patients went into preterm labour \& in those patients with cervical length $>3.0 \mathrm{~cm}, 71$ (9.59\%) landed up in preterm labour. When statistically analysed, the association between cervical length and gestational age at which labour started were very significant and results showed $x^{2}=190.01, \mathrm{df}=1, \mathrm{P}<0.0001$ (very significant ). As the cervical length increases, the median gestational age at which labour started also increases which was found to be significant $(\mathrm{r}=0.98, \mathrm{P}<0.01)$.

Conclusions: Shorter cervices lead to shorter gestations and early labour. Thus ultrasonographic measurement of cervical length at 18-24 weeks of gestation is very important, more so in asymptomatic women and can be utilized as a tool for predicting adverse pregnancy outcome especially preterm labour and delivery.
\end{abstract}

Keywords: Cervical length, Ultrasonography, Preterm labour, Preterm delivery, Cervical encirclage, Pregnancy outcome

\section{INTRODUCTION}

Preterm labour and preterm birth is the leading cause of perinatal mortality, whose incidence is approximately $10 \%$ of all live births worldwide, despite advances in perinatal care which leads to consequent perinatal morbidity and mortality. ${ }^{1}$ Preterm birth is responsible for a high neonatal mortality rate of $85 \%$ and even for those who survive, suffer numerous temporary and permanent disabilities as a sequelae. ${ }^{2}$ One can imagine the agony of life-long suffering because of mental, physical or intellectual impairment because of the sequelae of 
preterm birth on the person, his or her family, society and even the economies of the world. Preterm birth alone accounts for more than $70 \%$ of neonatal morbidity, mortality and healthcare expenses to the society. ${ }^{3}$

As they say, 'prevention is better than cure' which is absolutely true in case of preterm labour. It is seen that success rates in inhibiting labour once the process has started is poor, therefore over the past few decades the attention has shifted towards identifying the patients who are at risk for preterm birth and aggressive preventive programmes thereof. There are numerous pregnancy related complications which increase the risk of preterm birth, which the maternal risk scoring system fails to detect. $^{4}$

Since the clinical digital examination and cervical scoring and biochemical tests have very low sensitivity and specificity therefore these are almost of no use in clinical practice. $^{5,7}$

Over the last two decades the measurement of fetal fibronectin levels from cervico-vaginal secretions and cervical changes diagnosed by TVS have emerged as a promising prediction of preterm birth. ${ }^{8}$ It is now universally accepted that the shorter the cervical length, the greater is the risk of spontaneous pre-term labour. High resolution, non-invasive obstetric ultrasonography can help us measure alteration in the cervical anatomy accurately with the objectivity, safety and replicability which clinical digital examination and cervical scoring cannot provide. There are ample evidences in literature supporting the reliability of ultrasonographic evaluation of cervical shortening as measured by cervical length in assessment of the pre-term cervix. ${ }^{9}$

There are many studies which confirm the sensitivity of USG in measurement of the cervical length and a strong association between premature shortening of cervical length and preterm labour in high risk population. However, these studies do not provide USG evaluation of cervical length alteration in asymptomatic group. Hence the present study was undertaken with the purpose of delineating the cervical length changes in patients that will end up in preterm birth from cervical changes that end in term delivery, so that these cervical changes can be applied to the prevention and active management of those pregnant women suspected to be at risk for preterm labour and delivery.

\section{METHODS}

This study was a hospital based prospective one conducted in the dept. of Obstetrics and Gynaecology, Guwahati Medical College \& Hospital, Guwahati, Assam and Maharishi Markandeshwar Institute of Medical Science \& Research, Ambala, Haryana, India after getting proper approval from the Institutional Ethical Committees respectively.

\section{Selection of cases}

The patients were randomly selected after thorough history taking and detailed clinical examination after taking proper informed consent in written from each patient after being explained about the study. Those patients who fulfilled our inclusion and exclusion criteria were recruited for this study.

\section{Inclusion criteria}

Primigravida with singleton pregnancy without any high risk factors for preterm labour. Multigravida with normal, insignificant obstetric history. Period of gestation between 18 and 24 weeks.

\section{Exclusion criteria}

All high risk cases for preterm labour e.g. multiple gestation, Hypertensive disorders of pregnancy, intrauterine growth restriction, diabetes, past history of unexplained intrauterine fetal death, congenital uterine anomalies, polyhydramnios, ante partum hemorrhage cases who were lost to follow up.

\section{RESULTS}

In our study, majority of the patients were young, in the age group of 21 to 25 years $(30.49 \%)$ and only 30 $(2.12 \%)$ were above 35 years of age. 675 patients $(47.87 \%)$ were primigravidae, $67.17 \%$ were from the urban background and $61.70 \%$ hailed from the lower socio-economic stratum.

Table 1: Age wise distribution of the patients.

\begin{tabular}{|lll|}
\hline Age (years) & No of cases & Percentage (\%) \\
\hline $15-20$ & 310 & 21.98 \\
\hline $21-25$ & 430 & 30.49 \\
\hline $26-30$ & 400 & 28.36 \\
\hline $31-35$ & 240 & 17.05 \\
\hline$>35$ & 30 & 2.12 \\
\hline Total & 1410 & 100.00 \\
\hline
\end{tabular}

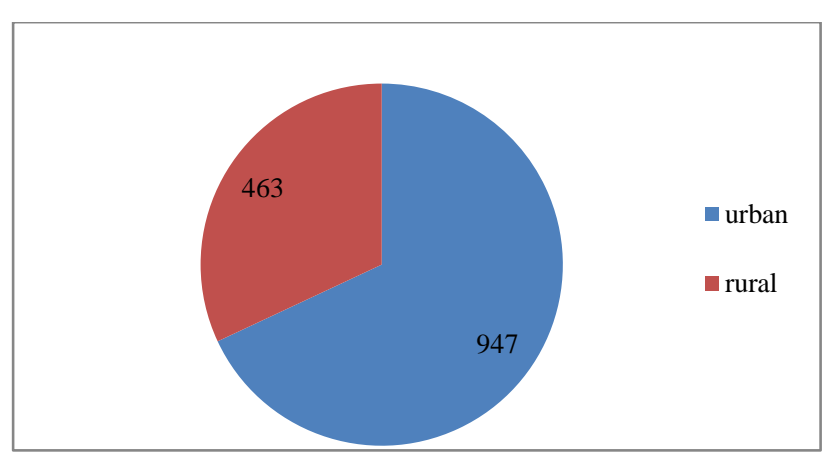

Figure 1: Urban-rural distribution. 
Table 2: Distribution of patients according to parity.

\begin{tabular}{|lll|}
\hline Parity & No of cases & Percentage (\%) \\
\hline $\mathrm{P}_{0}$ & 675 & 47.87 \\
\hline $\mathrm{P}_{1}$ & 369 & 26.17 \\
\hline $\mathrm{P}_{2}$ & 302 & 21.43 \\
\hline$>\mathrm{P}_{3}$ & 64 & 4.53 \\
\hline Total & 1410 & 100.00 \\
\hline
\end{tabular}

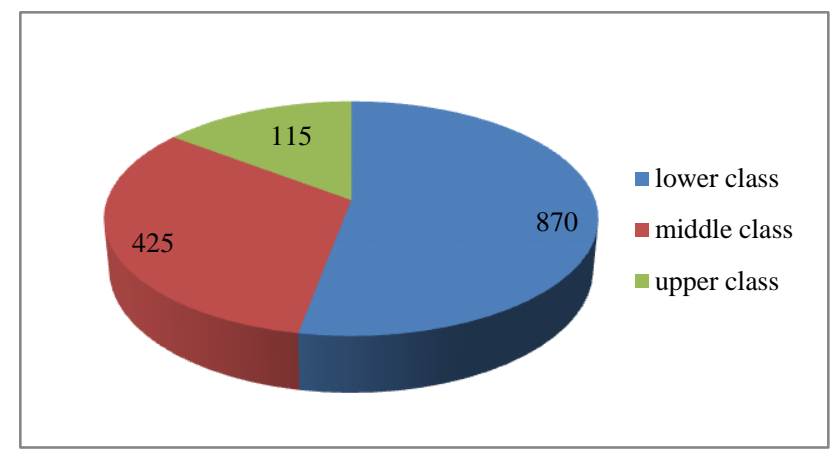

Figure 2: Socio-economic background.

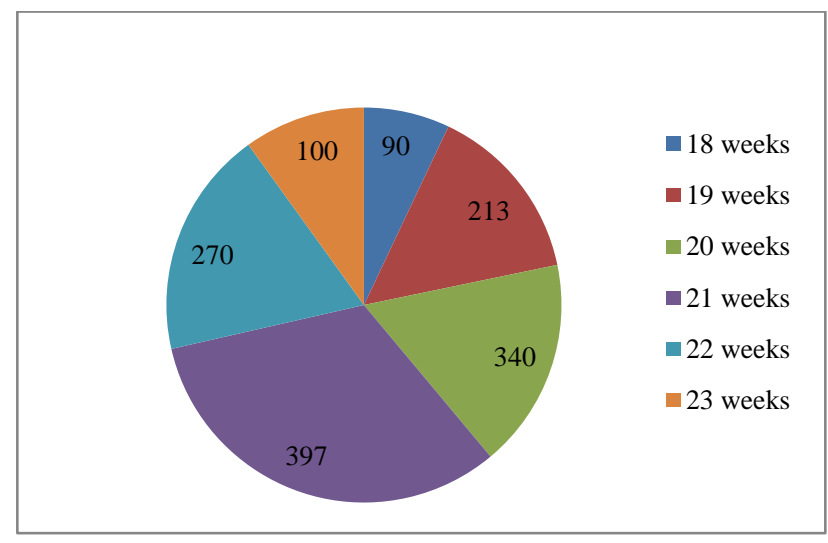

Figure 3: Distribution of cases according to gestational age.

Table 3: Distribution of mean cervical length by gestational age (weeks).

\begin{tabular}{|ll|}
\hline Gestational age (weeks) & Mean cervical length $(\mathbf{c m})$ \\
\hline 18 & 4.76 \\
\hline 19 & 4.12 \\
\hline 20 & 3.93 \\
\hline 21 & 3.77 \\
\hline 22 & 3.56 \\
\hline 23 & 3.43 \\
\hline 24 & 3.27 \\
\hline
\end{tabular}

In our study we found that as the cervical length reduced, the patients went into labour at an earlier gestational age, as evidenced by our results depicted in Table 4 below.

In our study, as depicted above, 360 patients went into preterm labour (25.54\%), 90 had post-term delivery
$(6.38 \%)$ and 960 patients delivered at term $(68.08 \%)$ (Table 5).

Table 4: Distribution of mean cervical length by gestational age (weeks) at which labour started.

\begin{tabular}{|lll|l|}
\hline $\begin{array}{l}\text { GA(weeks } \\
\text { at delivery }\end{array}$ & $\begin{array}{l}\text { Total no } \\
\text { of case }\end{array}$ & $\begin{array}{l}\text { Percentage } \\
(\%)\end{array}$ & $\begin{array}{l}\text { Mean cervical } \\
\text { length }(\mathrm{cm})\end{array}$ \\
\hline$\leq 28$ & 75 & 5.34 & 2.96 \\
\hline $29-32$ & 150 & 10.63 & 3.95 \\
\hline $33-36$ & 210 & 14.89 & 3.57 \\
\hline$\geq 37$ & 975 & 69.14 & 3.98 \\
\hline Total & 1410 & 100.00 & \\
\hline
\end{tabular}

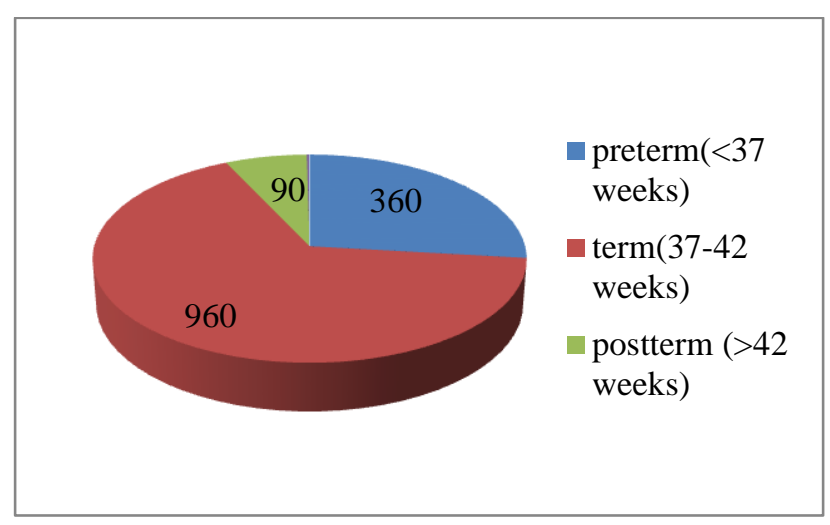

Figure 4: Gestational Age at which labour started (preterm, term, postterm).

Table 5: Distribution of labour according to the cervical length.

\begin{tabular}{|llll|}
\hline Cervical length & \multicolumn{2}{l|}{ Labour onset } \\
\hline $\mathbf{c m})$ & $\begin{array}{l}\text { Preterm } \\
(\%)\end{array}$ & $\begin{array}{l}\text { Term/postte } \\
\text { rm }(\%)\end{array}$ & Total \\
\hline$<1.5$ & $15(100.00)$ & $0(0.00)$ & $15(100.00)$ \\
\hline $1.5-2.0$ & $75(92.59)$ & $6(7.41)$ & $81(100.00)$ \\
\hline $2.1-2.5$ & $151(66.81)$ & $75(33.19)$ & $226(100.00)$ \\
\hline $2.6-3.0$ & $48(13.79)$ & $300(86.21)$ & $348(100.00)$ \\
\hline$>3.0$ & $71(9.59)$ & $669(90.41)$ & $740(100.00)$ \\
\hline Total & 360 & 1050 & 1410 \\
\hline
\end{tabular}

$\chi^{2}=190.01 ; \mathrm{df}=1, \mathrm{P}<0.0001$; (figures in brackets denote rowwise $\%)$.

The association between cervical length and gestational age at onset of labour was very significant $(\mathrm{P}<0.0001)$ (Table 6).

As is evident from Table 6, as the cervical length increases, the median gestational age (in weeks) at labour onset and delivery also increases and vice versa which was found to be statistically significant. ( $\mathrm{r}=0.98$, $\mathrm{P}<0.01)$. 
Table 6: Distribution of median gestational age at which labour started by cervical length.

\begin{tabular}{|lll|}
\hline $\begin{array}{l}\text { Cervical length } \\
(\mathrm{cm})\end{array}$ & & $\begin{array}{l}\text { Median gestational age at } \\
\text { delivery (weeks) }\end{array}$ \\
\hline$\leq 1.5$ & 15 & 32.50 \\
\hline $1.6-2.0$ & 110 & 33.00 \\
\hline $2.1-2.5$ & 210 & 34.10 \\
\hline $2.6-3.0$ & 385 & 36.60 \\
\hline$>3.0$ & 690 & 39.10 \\
\hline
\end{tabular}

\section{DISCUSSION}

We have restricted our study population in between 18 24 weeks of gestation so that it could coincide with the routine anomaly scan which almost every pregnant lady undergoes during her antenatal check-up. Also it is a known fact that cervical length is easier to measure and results more reliable in the second trimester than at later gestational ages.

Sonographic cervical length measurements were taken and recorded along with all other obstetrical sonological parameters e.g. BPD, HC, FL, liquor volume- pocket depth, amniotic fluid index, placenta, estimated fetal weight and composite gestational age. Cervical lengths measured at different gestation ages (between $18-24$ weeks) were tabulated, the mean value of cervical length was calculated and plotted in the graph against the corresponding gestation ages. It was observed that cervical length decreases linearly with increase in gestational age i.e. nearing term. The gestational age at which the patient went into labour started were noted and co-relation between the initially measured cervical length and GA at which labour started and all pregnancy and labour outcomes were noted, studied and plotted and then statistically analysed.

In our study we observed that the cervical length decreases linearly with increase in gestational age. Similar results were noted by Verma and Patel et al. ${ }^{7}$ When we plotted the gestational age at which labour started in the stratified cervical length group as $<1.5 \mathrm{~cm}$, $1.6-2.0,2-2.5,2.6-3$ and $>3 \mathrm{~cm}$, we found our results comparable to those reported by Hassan et al. In our study $360(25.54 \%)$ patients delivered pre term, 90 went into post-partum (6.38\%) and rest $960 \quad(68.08 \%)$ delivered at term, similar to those reported by Varma et al. $^{7}$

Of the 360 preterm labours, 75 were at $<28$ weeks (20.83\%), $150(41.66 \%)$ between 28-32 weeks, 155 $(43.05 \%)$ between $32-36^{\text {th }}$ week which were comparable to data published by Hassan et al (2000).

In our study we noted the mean cervical length and pre term and term labour as 2.29 week and $3.98 \mathrm{~cm}$ respectively which is similar to those reported by Berghella et al was 20.6 and $3.13 .^{8}$

In our study 21 patients out of which 16 had cervical length $\leq 1.5 \mathrm{~cm}$ and 5 had cervix $\leq 2.0 \mathrm{~cm}$ were subjected to cervical encirclage because of a history suggestive of cervical incompetence. 6 patients out of these had funneling of the cervical canal along with dilatation of the internal os with various degrees of membrane herniations. 2 encirclage procedures failed and 19 had successful term deliveries. Our results were comparable with those cited by Anderson et al. ${ }^{3}$

\section{CONCLUSION}

Thus we concluded that there is little doubt about the biological reality - "shorter cervices are associated with shorter gestations." Ultrasonological cervical length measurement can be a good tool for screening method for spontaneous preterm delivery and a cut off value for cervical length $(2.5 \mathrm{~cm})$ can be determined for intervention for the prevention of preterm labour. Our study demonstrates the usefulness and accuracy of Ultrasonography in cervical length measurement at 18-24 weeks of gestation in predicting and identifying the at risk patients for preterm labour and formulate strategies to prevent and manage the associated complications and improve the maternal and fetal morbidity scenario - thus ensuring a healthy mother and a healthy baby - the basic aim of providing quality obstetric care.

\section{Funding: No funding sources}

Conflict of interest: None declared

Ethical approval: The study was approved by the Institutional Ethics Committee

\section{REFERENCES}

1. Laing F, Mendelson E, Bohm-Velez M, Bree RL, Finberg H, Fishman EK, et al. Premature cervical dilatation. American College of Radiology. ACR Appropriateness Criteria. Radiology. 2000;215suppl (939-45).

2. Althiusius SM, Dekker GA, van Geijn HP. Cervical Incompetence. Obstetrics and Gynae surgery. 2002;57(6);377-87.

3. Anderson et al, USG and cervical ripening, Am J. Obstetrics Gynaecol., 2011, 15, 140 - 148.

4. Anderson, Turnbull AC. Cervical length and gestational age, Am J Obstet Gynecol. 2009; 105:1207-14.

5. Iams JD, Paraskos J, Landon MB, Teteris JN, Johnson FF. Cervical sonography in preterm labour. Obstet Gynecol. 1994;84(1):40-6.

6. Iams JD, Goldenberg RL, Mercer BM, Moawad A, Thom E, Meis PJ, et al. The Preterm Prediction Study: Recurrence Risk of preterm birth. Am J Obstet Gynecol. 2008;178:1035-40. 
7. Varma TR, Patel RH, Pillai U. Ultrasonograhic assessment of at risk patients. Acta Obstet Gynecol Scand. 1986;65(2):147-52.

8. Berghella V. The short and funneled cervix. Contemporary Obst Gynae. 2014;4:812-6.

9. Michaels WH, Montgomery C, Karo J, Temple J, Ager J, Olson J. Ultrasound differentiation of the competent from the incompetent cervix: prevention of preterm delivery. Am J Obstet Gynecol. 1986;154(3):537-46.

Cite this article as: Nath $\mathrm{J}$, Bhattacharjee AK, Talukdar RK. A clinical study on ultrasonographic measurement of cervical length at 18-24 weeks of gestation and pregnancy outcome. Int J Reprod Contracept Obstet Gynecol 2016;5:1088-92. 